\title{
Aortopulmonary Window Lymph Node
}

National Cancer Institute

\section{Source}

National Cancer Institute. Aortopulmonary Window Lymph Node. NCI Thesaurus. Code

C116165.

A lymph node located in the aortopulmonary window. 